\title{
Spatiotemporal Changes of Reference Evapotranspiration in Mongolia during 1980-2006
}

\author{
Wenjun Yu, ${ }^{1,2}$ Tonghua Wu, ${ }^{1}$ Weizhen Wang, ${ }^{1}$ Ren Li, ${ }^{1}$ Tianye Wang, ${ }^{1,2}$ Yanhui Qin, ${ }^{1,2}$ \\ Weihua Wang, ${ }^{1,2}$ and Xiaofan $\mathrm{Zhu}^{1,2}$ \\ ${ }^{1}$ Northwest Institute of Eco-Environment and Resources, Chinese Academy of Sciences, Lanzhou, Gansu 730000, China \\ ${ }^{2}$ University of Chinese Academy of Sciences, Beijing 100049, China
}

Correspondence should be addressed to Tonghua Wu; thuawu@lzb.ac.cn

Received 1 July 2016; Revised 20 October 2016; Accepted 23 October 2016

Academic Editor: Julio Diaz

Copyright (C) 2016 Wenjun Yu et al. This is an open access article distributed under the Creative Commons Attribution License, which permits unrestricted use, distribution, and reproduction in any medium, provided the original work is properly cited.

Reference evapotranspiration (RET) plays an important role in the terrestrial hydrological cycle. Applying the Penman-Monteith method, the RET over Mongolia was estimated from 1980 to 2006. The changing trends and magnitude of RET were detected by the Mann-Kendall test and Theil-Sen's slope methods. Meanwhile, aridity indices were estimated using two different indices. The impacts of meteorological variables on RET were assessed through sensitive analysis by comparing the resulting RETs from artificially disturbed meteorological variables. The results indicated that the RET for 16 stations in Mongolia showed an increasing trend, particularly in the center and south. The calculated RET was higher than precipitation, which means severe droughts in Mongolia. The spatial patterns of RET are significantly influenced by climatic conditions as well as characteristics of the underlying surface (e.g., elevation and vegetation). The mean annual RET decreased from the south to the north, owing to sparse vegetation in the south of Mongolia. The sensitivity analysis revealed that the changes of RET were strongly affected by air temperature and relative humidity.

\section{Introduction}

Evapotranspiration is used to describe the water cycle part of water loss from land surface into the atmosphere by the processes of both transpiration and evaporation, which plays an important role in the energy exchange processes between land and atmosphere. Therefore, evapotranspiration is considered as one of the indicators of climate and has great influence on the spatiotemporal changes of ecological hydrology. Reference evapotranspiration (RET) is defined as the atmospheric evaporation demand on a reference surface, which is a hypothetical grass reference crop with a height of $0.12 \mathrm{~m}$, fixed surface resistance of $70 \mathrm{~s} / \mathrm{m}$, and an albedo of 0.23 [1]. The RET assessment is the effective basis for estimating water demands of agricultural irrigation. As reported in previous studies $[2,3]$, there is a complementary relationship between RET and actual evapotranspiration. Thus, it is necessary to provide accurate determination of RET for agricultural water management.
Direct RET measurements are difficult to obtain; thus, numerous estimation methods have been developed, such as Penman-Monteith (P-M), Priestley-Taylor, and Hargreaves methods and the Makkink equation $[4,5]$. These models were derived either through field experiments or theoretically, which can be classified into groups such as temperature-based, radiation-based, and combination-based groups according to climatic parameters. Temperature- and radiation-based methods are beneficial for less input data, but the disadvantages are that local calibration is required and they do not account for aerodynamic resistance. In some specific regions where meteorological data is scarce and incomplete, it is necessary to adopt simplified models incorporating available meteorological data. The $\mathrm{P}-\mathrm{M}$ method was modified to account for varying reference surfaces by the Food and Agriculture Organization of the United Nations (FAO), which has several advantages similar to those of the lysimeters method under different conditions. The FAO P$\mathrm{M}$ method is a predominantly physical based approach and 
combines energy balance with mass transmission equation [6] considering resistance factors [7]. Also, the FAO P$\mathrm{M}$ method provides some procedures that could solve the problem of the availability of climatic parameters to estimate RET $[8,9]$. Vicente-Serrano et al. [10] compared the FAO $\mathrm{P}-\mathrm{M}$ method with eleven other methods to analyze the spatiotemporal changes of RET and assess the uncertainties associated with those methods. Heydari et al. [11] compared and evaluated 38 equations for RET in arid regions. Feng et al. [12] compared extreme learning machine, genetic algorithm, wavelet neural networks, and empirical RET models. These studies consistently show that the FAO P-M method is considered to be the most appropriate model to calculate the RET, which can be globally used, and has been widely tested under a broad range of climate conditions [13-15]. Talaee et al. [16] analyzed the RET trend on a seasonal and annual timescale by applying various statistical tools over Iran. Croitoru et al. [17] used the FAO P-M method to calculate RET with meteorological data from weather stations in Romania. Based on an overall analysis of the FAO P-M method and existing data, the FAO P-M method is a good choice to estimate RET in this study.

The spatial-temporal distribution of RET is extremely sensitive to climate change [18]. It is thus very important to understand the changes of RET under climate change for sustainable crop management. Some studies used the Mann-Kendall (M-K) test to analyze the temporal trends of RET estimated by the FAO P-M method [19-22]. The results show that RET trends differed regionally due to the effects of the regional climate. Mossad and Alazba [23] and Shadmani et al. [24] simulated the temporal variations of RET under an arid climate, while Gocic and Trajkovic [25] and Jhajharia et al. [26] calculated and analyzed the trends of RET under a humid climate. These studies indicated that change trends of RET might be different in similar climates and also might be similar in different climates. Therefore, for a specific region, it is necessary to figure out the contributions of climatic variables to regional RET variations. McVicar et al. [27] used different methods to study RET sensitivity to meteorological variables. Gong et al. [28] found that RET was most sensitive to relative humidity. Wang et al. [29] found that the downward changing trend of RET in the Heihe Basin of northwest China is mainly due to altering wind speed and relative humidity. Jhajharia and Singh [30] studied the contributions of meteorological variables to RET and attributed the RET decrease to decreased air temperature, wind speed, and solar radiation. Ambas and Baltas [31] found that the sensitive variables for RET, such as air temperature, wind speed, relative humidity, and solar radiation, differed as the spatiotemporal scales changed.

Mongolia is located in the center and east of Asia, which is characterized by an arid and semiarid climate. The evapotranspiration power is rather strong. The relatively sparse vegetation cover, weak field water capacity, and strong evapotranspiration jointly result in water shortages in Mongolia. In this study, the RET was estimated by FAO-56 P-M using the meteorological data in Mongolia and its changing trends and spatial distribution were analyzed. Meanwhile, drought

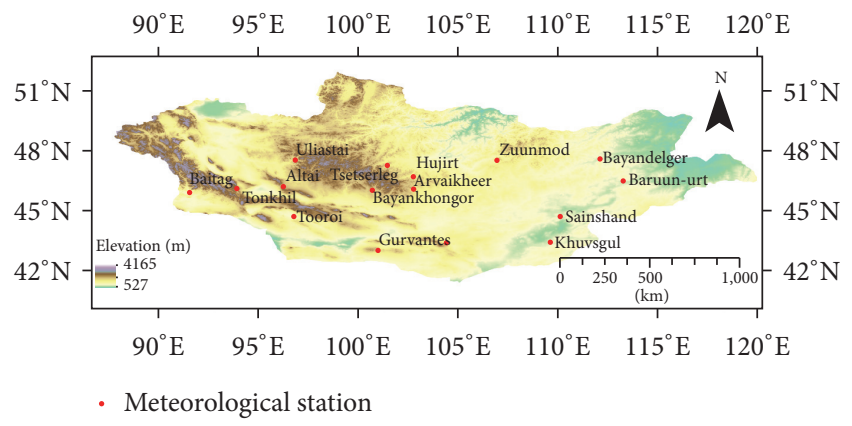

Figure 1: The DEM and distribution of meteorological stations in Mongolia.

conditions and the influence of meteorological variables on the RET were identified.

\section{Study Regions and Data Resource}

Mongolia is adjacent to China to the south and Russia to the north. The area of Mongolia is about 1.56 million $\mathrm{km}^{2}$ bounded approximately between $41.59^{\circ}$ and $52.14^{\circ}$ latitude and between $87.76^{\circ}$ and $119.93^{\circ}$ longitude. The average elevation is about $1500 \mathrm{~m}$ and decreases gradually from the west to the east. There is an extreme continental climate with long, cold winters and short summers. The mean annual precipitation of Mongolia is about $200 \mathrm{~mm}$, and the maximum precipitation is in summer. The seasonality in Mongolia is distinct. The highest air temperature is $30-35^{\circ} \mathrm{C}$ in the summer and the lowest is about $-45^{\circ} \mathrm{C}$ in winter. Permafrost is located in northern Mongolia. Land cover includes alpine meadows, aboriginal forest steppe, grassland, and desert from the north to the south. The area of the desert is large, accounting for about a quarter of the national territory.

The FAO P-M method was used to estimate the daily RET and requires daily variable meteorological data such as air temperature, wind speed at $2 \mathrm{~m}$, maximum and minimum air temperature, solar radiation, and vapor pressure. The last two variables can be estimated from the duration of bright sunshine and relative humidity, respectively. Air temperature, daily wind speed, relative humidity, atmospheric pressure, and precipitation from 1980 to 2006 were obtained from 16 available meteorological stations with international general meteorological observation instruments in Mongolia. Figure 1 shows the locations of these meteorological stations, and Table 1 lists the names, location, elevation, and land cover for each station. The sunshine hour data used to calculate daily solar radiation was downloaded from ECMWF (http://www.ecmwf.int/) because of the lack of observed sunshine hour data. Land cover and normalized difference vegetation index (NDVI) data only covered the period from 2001 to 2006, which was provided by NASA MODIS production.

\section{Methods}

3.1. The Penman-Monteith Method and Aridity Indices. The FAO-56 P-M method for the daily RET calculation assumes 
TABLE 1: The list of meteorological stations in the study area.

\begin{tabular}{|c|c|c|c|c|c|}
\hline ID & Name & Latitude & Longitude & Elevation $(\mathrm{m})$ & Land cover \\
\hline 1 & Gurvantes & $43.20 \mathrm{~N}$ & $101.00 \mathrm{E}$ & 1726 & Barren or sparsely vegetated \\
\hline 2 & Dalanzadgad & $43.58 \mathrm{~N}$ & $104.42 \mathrm{E}$ & 1462 & Urban and built-up \\
\hline 3 & Khuvsgul & $43.61 \mathrm{~N}$ & $109.63 \mathrm{E}$ & 993 & Barren or sparsely vegetated \\
\hline 4 & Sainshand & $44.90 \mathrm{~N}$ & $110.12 \mathrm{E}$ & 936 & Barren or sparsely vegetated \\
\hline 5 & Tooroi & $44.90 \mathrm{~N}$ & $96.77 \mathrm{E}$ & 1183 & Barren or sparsely vegetated \\
\hline 6 & Bayandelger & $47.78 \mathrm{~N}$ & $112.12 \mathrm{E}$ & 813 & Grassland \\
\hline 7 & Bayankhongor & $46.21 \mathrm{~N}$ & $100.71 \mathrm{E}$ & 1859 & Urban and built-up \\
\hline 8 & Baitag & $46.10 \mathrm{~N}$ & $91.55 \mathrm{E}$ & 1186 & Grasslands \\
\hline 9 & Arvaikheer & $46.27 \mathrm{~N}$ & $102.78 \mathrm{E}$ & 1813 & Urban and built-up \\
\hline 10 & Tonkhil & $46.30 \mathrm{~N}$ & $93.92 \mathrm{E}$ & 2222 & Barren or sparsely vegetated \\
\hline 11 & Altai & $46.40 \mathrm{~N}$ & $96.25 \mathrm{E}$ & 2180 & Grasslands \\
\hline 12 & Baruun-Urt & $46.68 \mathrm{~N}$ & $113.28 \mathrm{E}$ & 996 & Urban and built-up \\
\hline 13 & Hujirt & $46.90 \mathrm{~N}$ & $102.77 \mathrm{E}$ & 1662 & Urban and built-up \\
\hline 14 & Tsetserleg & $47.46 \mathrm{~N}$ & $101.46 \mathrm{E}$ & 1691 & Grasslands \\
\hline 15 & Zuunmod & $47.72 \mathrm{~N}$ & $106.95 \mathrm{E}$ & 1529 & Grasslands \\
\hline 16 & Uliastai & $47.73 \mathrm{~N}$ & $96.85 \mathrm{E}$ & 1751 & Grasslands \\
\hline
\end{tabular}

a hypothetical crop surface with a height of $12 \mathrm{~cm}$, having surface resistance of $70 \mathrm{~s} \mathrm{~m}^{-1}$ and an albedo of 0.23 , closely resembling the evaporation of an extension surface of green grass of uniform height, actively growing and adequately watered, which is given by (1). Considering the seasonal and annual changes of the RET because of the influence of climate change, monthly, seasonal, and annual RET series were analyzed and discussed in the study, which were formed by accumulating the daily RET:

$$
\begin{aligned}
& E T_{0} \\
& \qquad=\frac{0.408 \Delta\left(R_{n}-G\right)+\gamma(900 /(T+273)) u_{2}\left(e_{s}-e_{a}\right)}{\Delta+\gamma\left(1+0.34 u_{2}\right)},
\end{aligned}
$$

where $E T_{0}$ is daily reference evapotranspiration $\left(\mathrm{mm} \mathrm{d}^{-1}\right) ; R_{n}$ is daily net radiation at the crop surface $\left(\mathrm{MJ} \mathrm{m}^{-2} \mathrm{~d}^{-1}\right) ; G$ is soil heat flux $\left(\mathrm{MJ} \mathrm{m}^{-2} \mathrm{~d}^{-1}\right) ; T$ is mean daily air temperature at $2 \mathrm{~m}$ $\left({ }^{\circ} \mathrm{C}\right) ; U_{2}$ is mean daily wind speed at $2 \mathrm{~m}\left(\mathrm{~m} \mathrm{~s}^{-1}\right) ; e_{s}$ is mean saturated vapor pressure $(\mathrm{kPa})$, which can be calculated from the air temperature; $e_{a}$ is actual vapor pressure $(\mathrm{kPa})$ derived from relative humidity data; $\left(e_{s}-e_{a}\right)$ means the saturation vapor pressure deficit $(\mathrm{kPa}) ; \Delta$ is the slope of saturated vapor pressure curve $\left(\mathrm{kPa}^{\circ} \mathrm{C}^{-1}\right)$; and $\gamma$ is the psychrometric constant $\left(\mathrm{kPa}^{\circ} \mathrm{C}^{-1}\right)$.

The daily net radiation data is derived from shortwave radiation with the duration of bright sunshine (hours per day). The net shortwave radiation resulting from the balance between incoming and reflected solar radiation is given by (3). The rate of longwave energy emission is proportional to absolute temperature of the surface raised to the fourth power. This relation is expressed quantitatively by the StefanBoltzmann law as presented in (4). Net radiation is the difference between incoming net shortwave radiation and outgoing net longwave radiation; hence,

$$
\begin{aligned}
R_{S} & =\left(a_{s}+b_{s} \frac{n}{N}\right) R_{a}, \\
R_{n s} & =(1-\alpha) R_{S}, \\
R_{n l} & =\sigma\left[\frac{T_{\max , K}^{4}+T_{\min , K}^{4}}{2}\right]\left(0.34-0.14 \sqrt{e_{a}}\right) \\
& \cdot\left(1.35 \frac{R_{s}}{R_{s o}}-0.35\right), \\
R_{n} & =R_{n l}-R_{n s},
\end{aligned}
$$

where $R_{s}$ is shortwave radiation $\left(\mathrm{MJ} \mathrm{m}^{-2} \mathrm{~d}^{-1}\right) ; n$ is actual duration of sunshine (hour); $N$ is maximum possible duration of sunshine or daylight hours (hour); $R_{a}$ is extraterrestrial radiation $\left(\mathrm{MJ} \mathrm{m}^{-2} \mathrm{~d}^{-1}\right) ; a_{s}$ is the regression constant, expressing the fraction of extraterrestrial radiation reaching the earth on overcast days $(n=0)$; and $\left(a_{s}+b_{s}\right)$ is the fraction of extraterrestrial radiation reaching the earth on clear days $(n=N)$. Where no actual solar radiation data are available and no calibration has been carried out for improved $a_{s}$ and $b_{s}$ parameters, the values $a_{s}=0.25$ and $b_{s}=0.50$ are recommended. $R_{n s}$ is net shortwave radiation $\left(\mathrm{MJ} \mathrm{m}^{-2} \mathrm{~d}^{-1}\right)$; $\alpha$ is the albedo or canopy reflection coefficient, which is 0.23 for the hypothetical grass reference crop; $R_{n l}$ is net outgoing longwave radiation $\left(\mathrm{MJ} \mathrm{m}^{-2} \mathrm{~d}^{-1}\right) ; \sigma$ is the Stefan-Boltzmann constant; $T_{\max , K}$ is maximum absolute temperature during a 24-hour period $\left(K={ }^{\circ} \mathrm{C}+273.15\right) ; T_{\min , K}$ is minimum absolute temperature during a 24-hour period $\left(K={ }^{\circ} \mathrm{C}+273.15\right) ; e_{a}$ is actual vapor pressure $(\mathrm{kPa}) ; R_{s o}$ is clear-sky solar radiation $\left(\mathrm{MJ} \mathrm{m} \mathrm{m}^{-2} \mathrm{~d}^{-1}\right)$.

Complex models are available to describe soil heat flux. Considering that soil heat flux is relatively small compared 
to net radiation, particularly when the surface is covered by vegetation and the calculation time steps are 24 hours or longer, the soil heat flux may be ignored and $G=0$ in this study.

The aridity index represents the dryness condition and can be derived from precipitation and RET. The dry degree AI is one of the most frequently used methods, which is expressed in

$$
\mathrm{AI}=\frac{\left(E T_{0}-P\right)}{E T_{0}},
$$

where $E T_{0}$ is reference evapotranspiration and $P$ is accumulative precipitation. The closer the AI is to one, the drier the climate is in the study area.

The de Martonne index $J\left(\mathrm{~mm} /{ }^{\circ} \mathrm{C}\right)$ is another commonly used aridity index taking monthly values of precipitation and air temperature but without considering $E T_{0}$ as presented in

$$
J=\frac{12 P}{T+10}
$$

where $P$ and $T$ are monthly total precipitation $(\mathrm{mm})$ and air temperature $\left({ }^{\circ} \mathrm{C}\right)$, respectively. The drought condition can be observable when the index is less than $30 \mathrm{~mm} /{ }^{\circ} \mathrm{C}$ and severe drought may occur when it becomes less than $20 \mathrm{~mm} /{ }^{\circ} \mathrm{C}$.

3.2. Trend Change Detection. The Mann-Kendall test [32, 33] is a nonparametric method to identify trend change within variables. This method has been used in other studies that aimed to understand trends in the time series of climate variables such as precipitation, runoff, and evapotranspiration for a long term, as long as they are independent of each other [3436]. The magnitude of the trend can be estimated by ThielSen's slope $[37,38]$.

We applied the $\mathrm{M}-\mathrm{K}$ test for detecting change trend in RET. The test statistic $S$ is estimated by

$$
\begin{array}{r}
S=\sum_{j=1}^{n-1} \sum_{k=j+1}^{n} \operatorname{sgn}\left(x_{k}-x_{j}\right), \\
\operatorname{sgn}\left(x_{k}-x_{j}\right)= \begin{cases}1 & x_{k}-x_{j}>0 \\
0 & x_{k}-x_{j}=0 \\
-0 & x_{k}-x_{j}<0,\end{cases}
\end{array}
$$

where $x$ denotes individual data values; $n$ denotes total number of data; sgn is a signal function as defined in (5).

The statistic $S$ is normally distributed when $n>10$. The variance (Var) of $S$ is given in

$$
\begin{aligned}
& \operatorname{Var}(S) \\
& \quad=\frac{1}{18}\left[n(n-1)(2 n+5)-\sum_{i=1}^{n} t_{i}\left(t_{i}-1\right)\left(2 t_{i}+5\right)\right],
\end{aligned}
$$

where $t_{i}$ is the number of ties of extent $i$. The test statistic $z$ therefore can be estimated by (10). Positive $z$ indicates an increasing trend, and vice versa:

$$
z= \begin{cases}\frac{s-1}{\sqrt{\operatorname{Var}(S)}} & S>0 \\ 0 & S=0 \\ \frac{s+1}{\sqrt{\operatorname{Var}(S)}} & S<0 .\end{cases}
$$

The Thiel-Sen approach was used to estimate the slope of changing RET. The advantage of this method is that it limits the influence of the outliers on the slope in comparison with the linear regression. In (11), $b$ is the estimated trend slope of the given data series:

$$
b=\operatorname{median}\left(\frac{x_{k}-x_{j}}{k-j}\right), \quad \forall j<k .
$$

3.3. Sensitivity Analysis. Air temperature, relative humidity, wind speed, and sunshine hours are important parameters in the FAO-56 P-M method and their contributions to RET may be different. Furthermore, unused precipitation also affects the variations of RET. Thus, correlation and sensitivity analyses were performed to assess the impact of meteorological variables on RET.

Nine series of RETs were first generated from different groups of meteorological (observed and artificial) datasets. The original RET series was calculated from the observed meteorological variables, and the extra RET series are from eight groups of artificial meteorological variables. The first four groups were generated by removing the trend of each meteorological variable individually while keeping the others constant. Taking air temperature as an example, we calculated the average value and substituted it for real observations. Then, the replaced air temperature together with other observed meteorological variables constitutes one group of artificial meteorological variables. The other three groups could be generated in the same manner. The second four groups were generated by evenly increasing the value of each meteorological variable by $10 \%$ while keeping the others unchanged. Comparing the eight series of estimated RETs with the original one, the influence of meteorological variables on RET could be quantitatively assessed using monthly and annual trends and correlation coefficients.

\section{Results and Discussion}

4.1. Variations of RET and Aridity Indices. Figures 2(a) and 2(b) show the average monthly series for precipitation $(P)$, RET, and aridity indices (AI and $J$ ) of all stations in Mongolia during 1980-2006. The mean monthly RET is about $70 \mathrm{~mm}$. The maximum value of $150 \mathrm{~mm}$ per month appears in summer (July), and the minimum value of only about $15 \mathrm{~mm}$ per month appears in winter. The RET in summer accounts for a total of $50 \%$ in a year. Precipitation also reaches a peak in summer (June-August). Precipitation is maximal in July with a monthly average of just about $50 \mathrm{~mm}$. The aridity index AI 

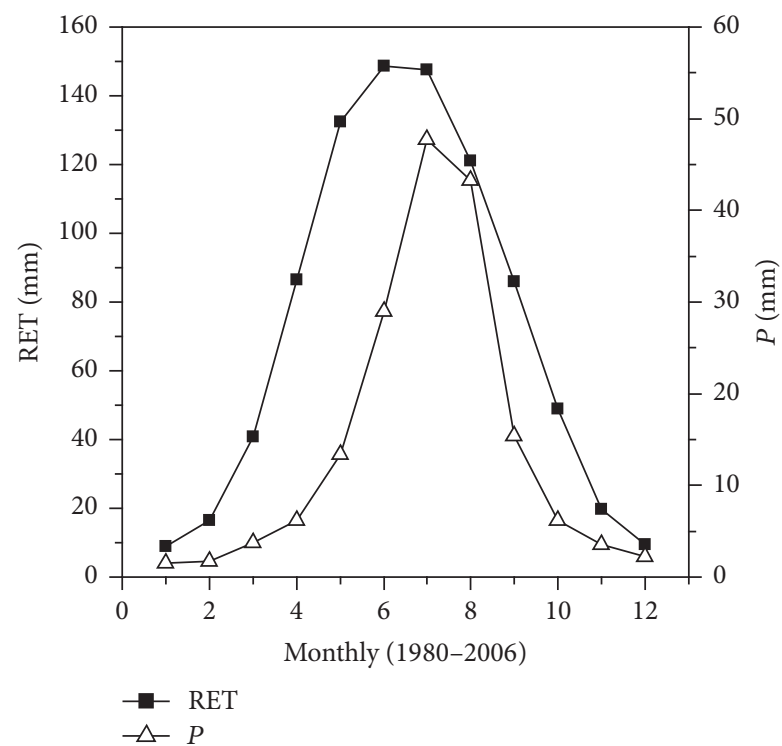

(a)

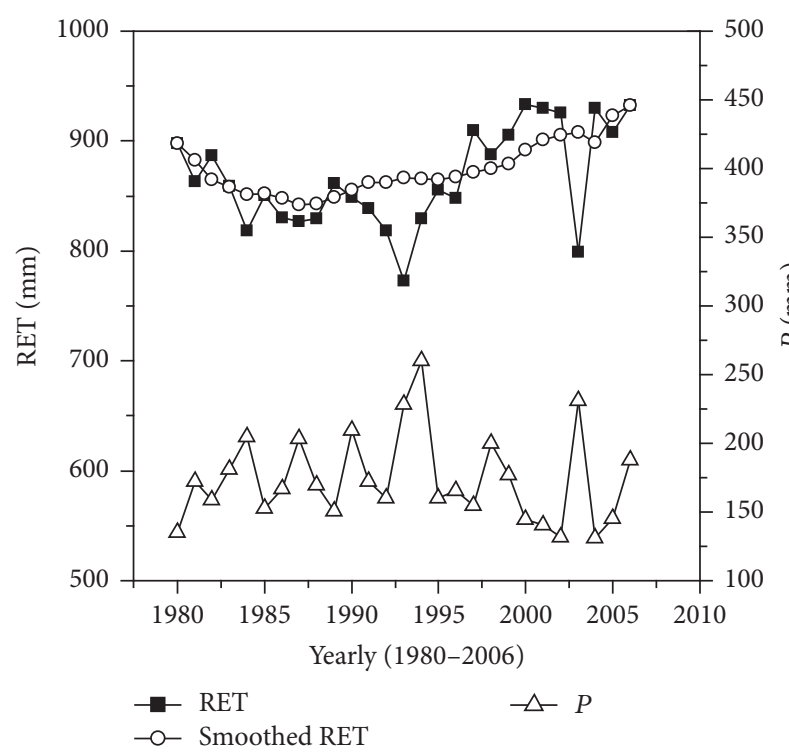

(c)

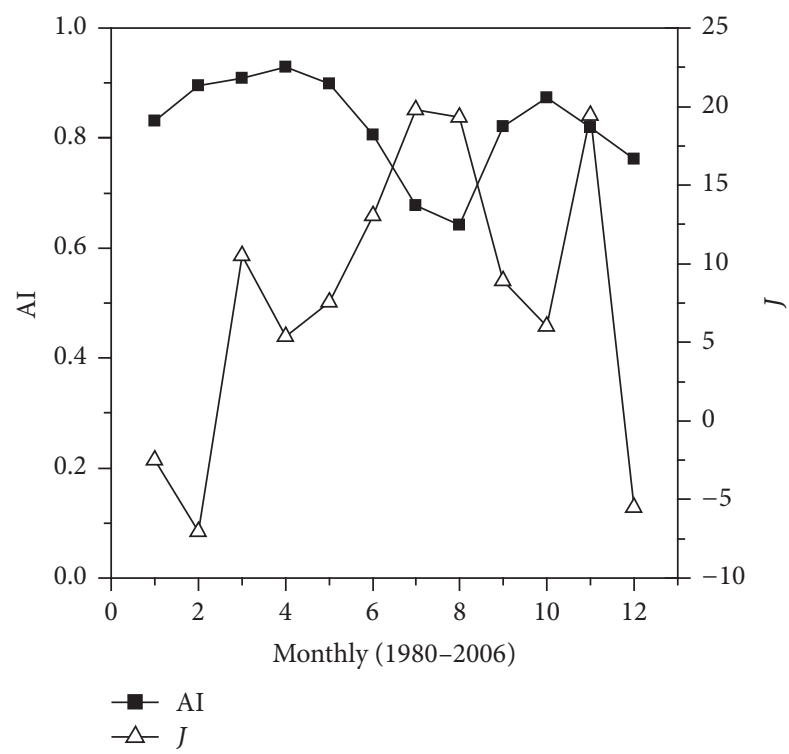

(b)

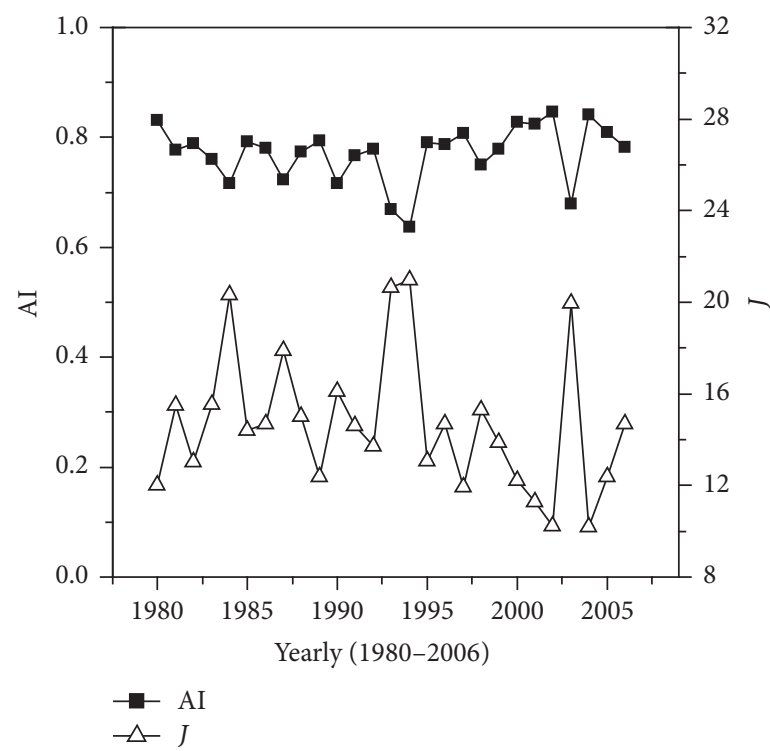

(d)

Figure 2: Annual and monthly changes of $P$, RET, and aridity indices.

presents a peak and de Martonne index $J$ presents a valley in summer. The average AI is 0.82 , is close to 1.0 in spring and winter, and drops to the lowest of about 0.6 in summer, indicating drier conditions in spring and winter. The index $J$ was calculated to be less than 20 and sometimes negative. The smaller the value of $J$, the more severe the drought condition. Both indices indicate severe droughts in Mongolia.

Figures 2(c) and 2(d) present trends on an annual scale for RET, smoothed RET, precipitation, and aridity indices (AI and $J$ ). The average annual RET is $866.45 \mathrm{~mm}$. The smoothed RET shows a generally upward trend over the past 27 years. A slow downward trend has been observed in the early stage from 1980 to 1993 and an ascending trend has been observed from 1994 to 2006 . The average annual aridity indices of AI and $J$ are 0.77 and 14.6, respectively, and precipitation is much less than RET, presenting extremely dry conditions in Mongolia over the past 27 years. The aridity indices maintain an almost stable level and $J$ presents a decreasing trend in Figure 2(b), signifying upcoming severe drought in Mongolia.

The RET shows an increasing trend over the past 27 years in Mongolia and is likely to keep increasing in the near future. These findings are consistent with the results of other studies. $\mathrm{Mu}$ et al. [39, 40] developed a globe evapotranspiration algorithm which was used to produce the MODIS evapotranspiration dataset, which reported different change trends of RET across the world and rising RET in Mongolia. The GDAS-based RET was evaluated to be a 


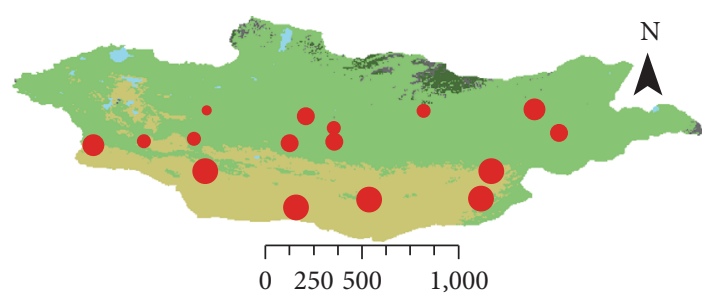

$(\mathrm{km})$

$$
\begin{aligned}
& \text { - Others } \\
& \text { - Water } \\
& \text { - Mixed forests } \\
& \text { - Grasslands } \\
& \text { - Barren or sparsely vegetated }
\end{aligned}
$$$$
\begin{array}{ll}
\text { - } & T<-2.0 \\
& -2.0 \leq T<0 \\
\text { - } & 0 \leq T<2.0 \\
\text { } & 2.0 \leq T<4.0 \\
& 4.0 \leq T<6.0
\end{array}
$$

(a)

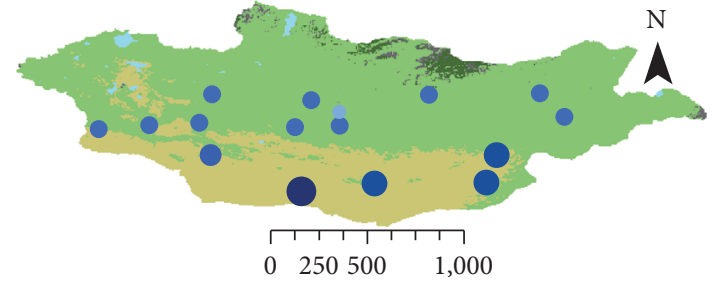

$(\mathrm{km})$

$$
\begin{aligned}
& \text { - Others } \\
& \text { - Water } \\
& \text { - Mixed forests } \\
& \text { - Grasslands } \\
& \text { - Barren or sparsely vegetated }
\end{aligned}
$$

$$
\begin{aligned}
& \text { RET }<750 \\
& 750 \leq \mathrm{RET}<800 \\
& 800 \leq \mathrm{RET}<850 \\
& 850 \leq \mathrm{RET}<900 \\
& \\
& 900 \leq \mathrm{RET}<950
\end{aligned}
$$

(b)

FIGURE 3: Distributions of average annual air temperature (a) and RET (b).

reliable dataset [41], in which the average RET in Mongolia is estimated to be about 4 to $5 \mathrm{~mm}$ per day in July, quite similar to the intensity of about $150 \mathrm{~mm}$ in July as presented in Figure 2.

4.2. Spatial-Temporal Variations of RET. There are distinct regional differences of land cover from NASA MODIS production in Mongolia from the north to the south. Also, there was almost no change of land cover during 2001 to 2006 (Table 2); thus, land cover data for only 2006 is presented in this study (Figure 3). More than one-quarter of land area in Mongolia is barren or desert in the south. Vegetation in northern Mongolia increases, which is dominated by grasslands (Table 2). The area of waterbodies is very small and cannot be a main source of evaporation. Evapotranspiration in barren or desert areas is just from the soil water without transpiration from vegetation. If there was enough soil water, evapotranspiration in barren or desert areas would be huge. This means that RET in barren or desert areas is much more than in areas covered by vegetation or buildings. The distribution of average annual air temperature is presented in Figure 3(a). The average annual air temperature in the south is about $5^{\circ} \mathrm{C}$ and below $0^{\circ} \mathrm{C}$ in the north. The annual air temperature decreases from the south to the north, while vegetation cover increased from the south to the north. Without the influence of vegetation, the average annual air temperature in the south with barren or desert areas is much higher than that in the north (Figure 3(a)). Gerelchuluun and Ahn [42] used the Weather Research and Forecast model to attain air temperature distribution from 1981 to 2010 with the limited station network in Mongolia. It was also discovered that air temperature in the south was higher than that in the north. The effects of the combination of climate and land cover result in different distributions of RET as seen in Figure 3(b). The magnitude of mean annual RET at the same land cover is similar, which is $850-950 \mathrm{~mm}$ in barren or desert areas and $750-850 \mathrm{~mm}$ in grasslands. The mean annual RET in the south with high air temperature and no vegetation is much larger than that in the north, denoting adequate water supplement. Surface coverage influences
TABLE 2: Fractions of land covers.

\begin{tabular}{lcccccc}
\hline & $\begin{array}{c}2001 \\
(\%)\end{array}$ & $\begin{array}{c}2002 \\
(\%)\end{array}$ & $\begin{array}{c}2003 \\
(\%)\end{array}$ & $\begin{array}{c}2004 \\
(\%)\end{array}$ & $\begin{array}{c}2005 \\
(\%)\end{array}$ & $\begin{array}{c}2006 \\
(\%)\end{array}$ \\
\hline Water & 0.82 & 0.82 & 0.83 & 0.82 & 0.81 & 0.80 \\
$\begin{array}{l}\text { Mixed } \\
\text { forests }\end{array}$ & 1.66 & 1.59 & 1.43 & 1.34 & 1.28 & 1.49 \\
$\begin{array}{l}\text { Grasslands } \\
\begin{array}{l}\text { Barren or } \\
\text { sparsely }\end{array}\end{array}$ & 66.33 & 67.51 & 68.52 & 69.32 & 68.20 & 68.78 \\
vegetated & 29.24 & 28.91 & 28.26 & 27.43 & 28.35 & 27.83 \\
\hline
\end{tabular}

meteorological variables, which changes the distribution of RET. Thus, although there are almost no stations in the north, the results of distribution condition of RET in Mongolia may be accepted.

Elevation and latitude are important factors impacting the change of RET. The RET declines with the ascent of latitude and elevation (Figure 4, Table 3). The slope values of trend lines are -19.9 and -34.45 for the change RET with the ascent of latitude and elevation, respectively. The declining trend of RET with the ascent of latitude is much clearer than that of RET with the ascent of elevation. The most distinct change of RET with the ascent of elevation and latitude appears in summer (Figure 5). There is almost no influence for the change of RET with the ascent of elevation and latitude in winter. The trend changes of RET in spring and autumn are similar with the ascent of elevation and latitude. Air temperature is the main influencing factor for the change of RET, as it may decline with the ascent of elevation and latitude leading to the declining trend of RET.

The seasonal and annual change of climate and vegetation in Mongolia determined the similar change characteristic of RET. Thus, the trend changes of RET are detected by the $\mathrm{M}-\mathrm{K}$ test on annual and seasonal scales at the stations on a nationwide image of the NDVI distribution. The relationship between RET and NDVI is complex as presented in previous studies $[43,44]$. The correlation between RET and NDVI is not significant. It thus confirms that the effects of NDVI 


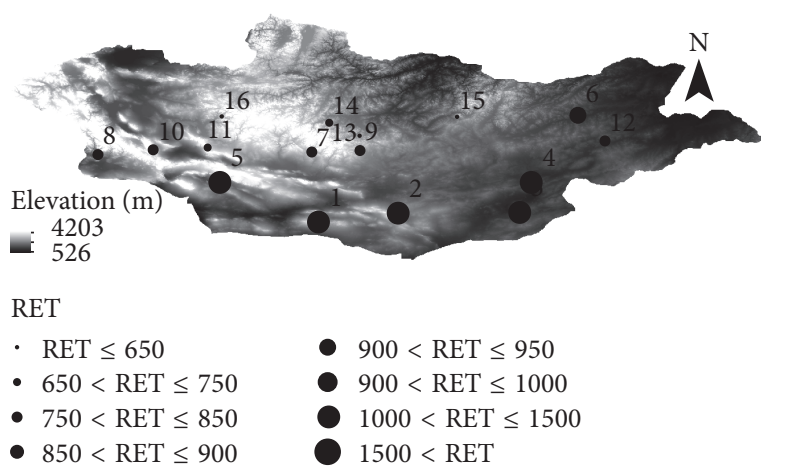

(a)

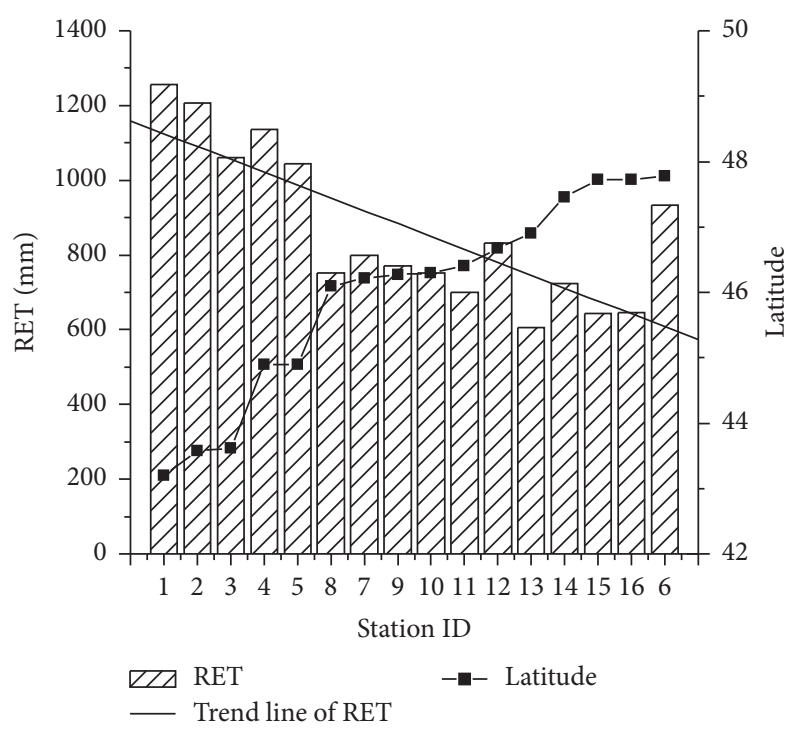

(b)

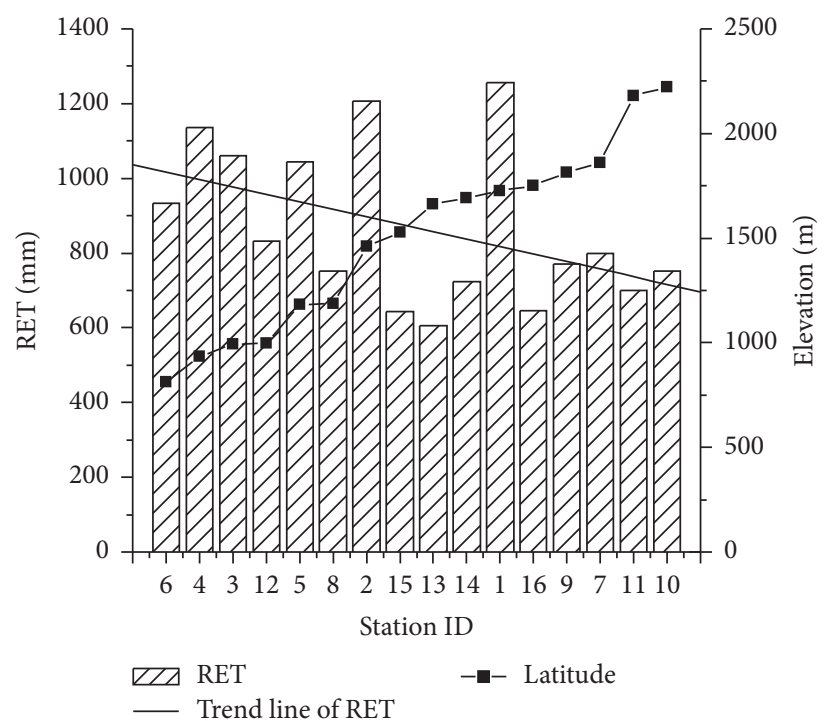

(c)

FIGURE 4: The distribution of mean annual RET for each station based on DEM (a) and its diagrams sorting by latitude (b) and elevation (c), respectively.

TABLE 3: The average RET for different latitude and elevation.

\begin{tabular}{lcccc}
\hline Elevation $(\mathrm{m})$ & $<1000$ & $1000-1500$ & $1500-1800$ & $>1800$ \\
\hline Number of sits & 4 & 4 & 4 & 4 \\
RET $(\mathrm{mm})$ & 990.43 & 911.39 & 808.62 & 776.57 \\
\hline Latitude $\left(^{\circ}\right)$ & $<44$ & $44-45$ & $45-46$ & $>46$ \\
\hline Number of sits & 3 & 2 & 7 & 4 \\
RET $(\mathrm{mm})$ & 1410.74 & 987.33 & 961.62 & 837.50 \\
\hline
\end{tabular}

and land cover on RET are complex and nonlinear in nature. Considering the large variations of Theil-Sen's slope $b$ values in different periods, the legends in Figure 6 were not fixed in order to better distinguish the changes of RET at each station. On both annual and seasonal scales, the RET increased at most stations in the middle of Mongolia. The increase of RET on an annual scale is presented in Figure 6(a), and the distinct upward trends of annual RET at some stations in the center and south of Mongolia are the most significant. Figures 6(b), 6(c), and 6(d) indicate upward trends of RET at stations in the center and south of Mongolia for spring (FebruaryApril), summer (May-July), and autumn (August-October). In particular, there is only one station in the middle of Mongolia with decreasing RET in autumn, while multiple stations show decreasing RET in spring and summer. It may be the effects of the decreasing NDVI that could lead to possibly much more soil water supply for increasing RET. However, the maximum $b$, indicating the largest increment, occurs in summer as result of the highest air temperature. In winter (November-January in next year), the RET is 

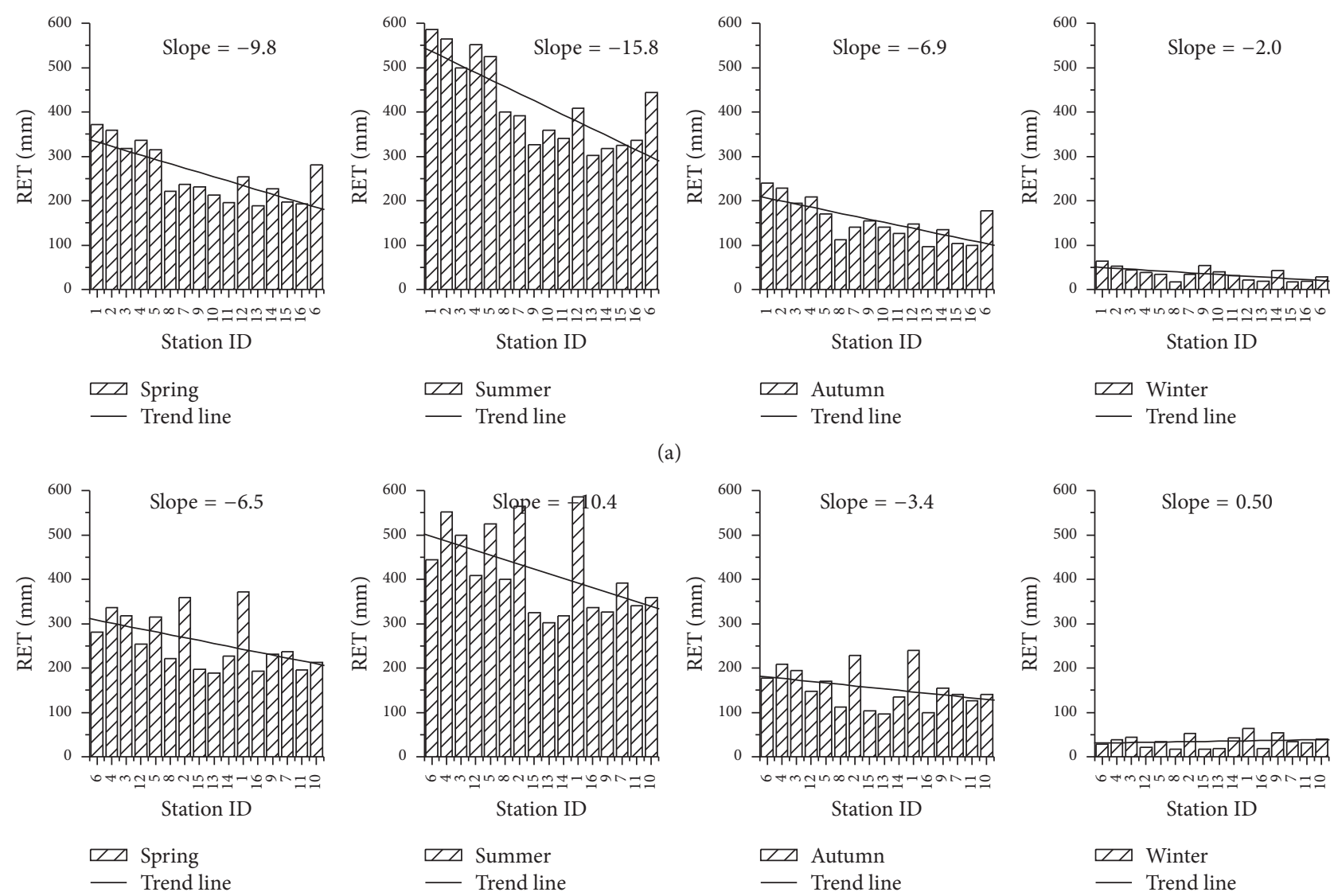

FIGURE 5: The mean seasonal RET for each station sorting by latitude (a) and elevation (b), respectively.

increasing at stations in southernmost Mongolia with just two stations having high $b$ values. Although there was decreasing NDVI, the lower air temperature seriously influenced the change of RET. Thus, slope $b$ values of most stations were smaller than in other seasons. The test statistics $z$ and TheilSen's slope $b$ values are presented in Figure 6. The most statistic values $(z$ and $b$ ) at sites are positive on a seasonal and annual scale, which illustrate consistent upward trends of RET in Mongolia. The average annual $b$ value is 2.65 which shows a slow increase of RET over the past 27 years. It was found that there are larger $z$ and $b$ values in warm seasons (summer and autumn). It is clear that the upward trends are faster in warm seasons, due to high air temperature and a high proportion of rainfall in these seasons. Moreover, the slope $b$ values in summer are the largest among those in all seasons but positive $b$ is also found at most stations in autumn. This means that summer has some rapid increases of RET, while autumn has slow increases but larger area upwards of RET.

4.3. Variations of Meteorological Variables and Correlations to $R E T$. The RET is influenced by meteorological variables as well as surface conditions such as distance from the ocean, land cover, and topography. In Mongolia, the difference of these factors causes diverse RET spatial distributions. The change characteristic of RET and meteorological variables
TABLE 4: Correlation coefficients of RET and related meteorological variables. $*$ is the significant level of 0.05 , and $* *$ is the significant level of 0.01 .

\begin{tabular}{lccccc}
\hline \multirow{2}{*}{ RET } & $\begin{array}{l}\text { Wind } \\
\text { speed }\end{array}$ & $\begin{array}{c}\text { Relative } \\
\text { humidity }\end{array}$ & $\begin{array}{c}\text { Air } \\
\text { temperature }\end{array}$ & $\begin{array}{c}\text { Sunshine } \\
\text { hour }\end{array}$ & Precipitation \\
\hline Annual & $0.447^{*}$ & $-0.611^{* *}$ & $0.594^{* *}$ & 0.362 & $-0.648^{* *}$ \\
Spring & $0.422^{*}$ & $-0.741^{* *}$ & $0.655^{* *}$ & $0.556^{* *}$ & -0.375 \\
Summer & 0.228 & $-0.899^{* *}$ & 0.879 & $0.404^{*}$ & $-0.804^{* *}$ \\
Autumn & 0.152 & $-0.586^{* *}$ & $0.734^{* *}$ & $0.419^{*}$ & $-0.435^{*}$ \\
Winter & 0.171 & $-0.565^{* *}$ & $0.480^{*}$ & 0.224 & -0.296 \\
\hline
\end{tabular}

are closely related. The impact of meteorological factors on RET is the most direct, which is concerned in terms of environment change and agriculture management, and so forth. In Figure 7, the annual changes of RET and related meteorological variables from 1980 to 2006 are presented, while statistic results of the correlation analysis on seasonal and annual scales are presented in Table 4. Distinct increases of RET are found as well as air temperature and solar radiation. The high positive correlation coefficient of RET and air temperature indicates that air temperature was the main reason for the increases of RET over the past 27 years. The upward trend of solar radiation was important to 

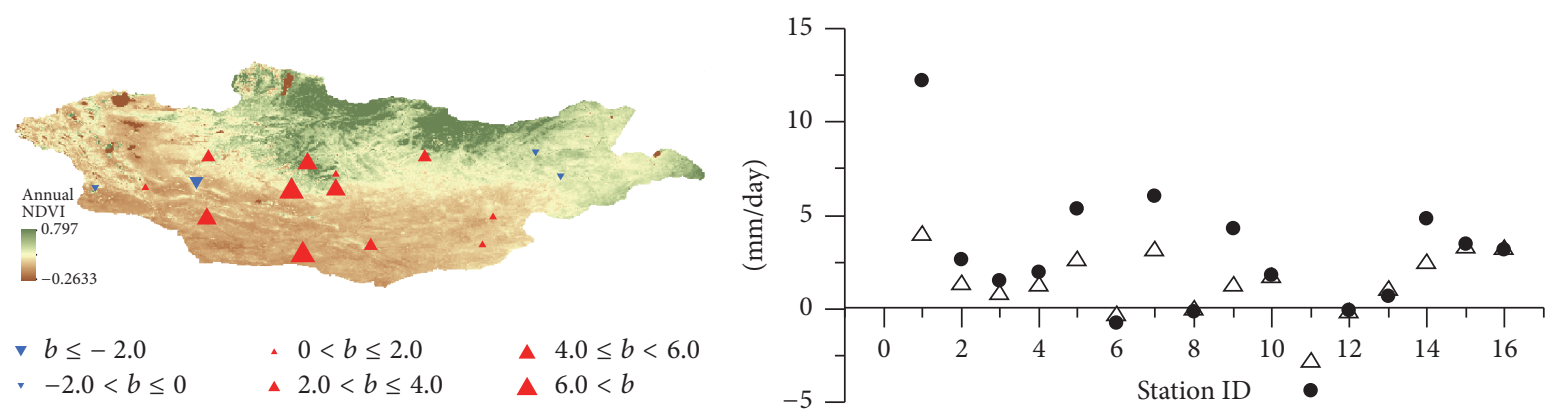

$\triangle$ Annual $z$

- Annual $b$

(a)

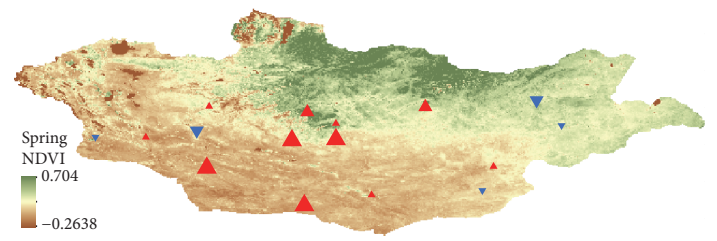

$\checkmark b \leq-0.5 \quad \Delta 0<b \leq 0.5$

- $1.0<b \leq 1.5$

- $-0.5<b \leq 0 \quad \Delta 0.5<b \leq 1.0$

$\Delta 1.5<b$

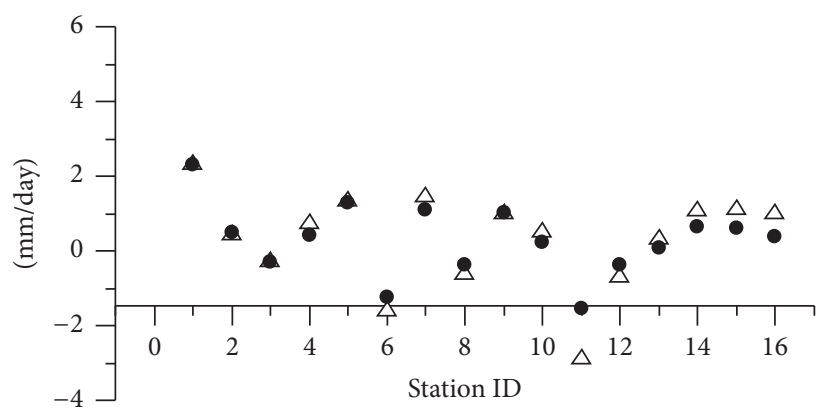

$\triangle$ Spring $z$

- Spring $b$

(b)

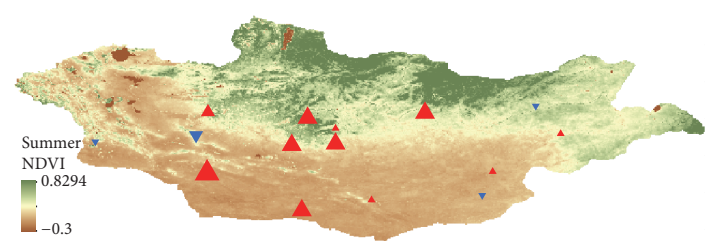

$\checkmark b \leq-1.0$

- $0<b \leq 1.0$

- $2.0<b \leq 3.0$

$-1.0<b \leq 0$

$\Delta 1.0<b \leq 2.0$

$\Delta 3.0<b$

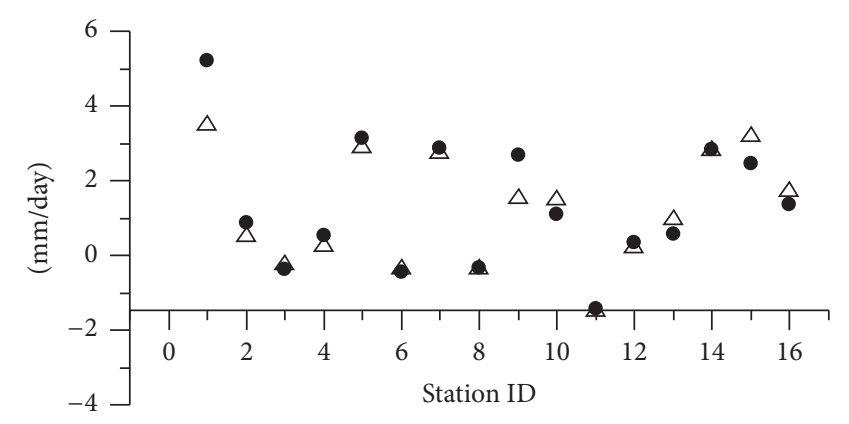

$\triangle$ Summer $z$

- Summer $b$

(c)

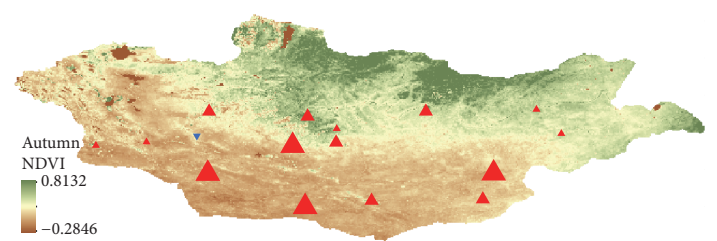

- $b \leq 0$

A $0.4<b \leq 0.8$

- $1.2<b \leq 1.6$

- $0<b \leq 0.4$

A $0.8<b \leq 1.2$

- $1.6<b$

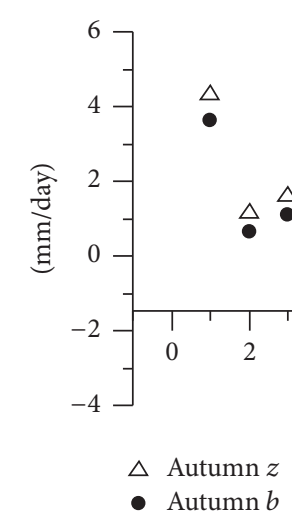

(d)

FIgURe 6: Continued. 

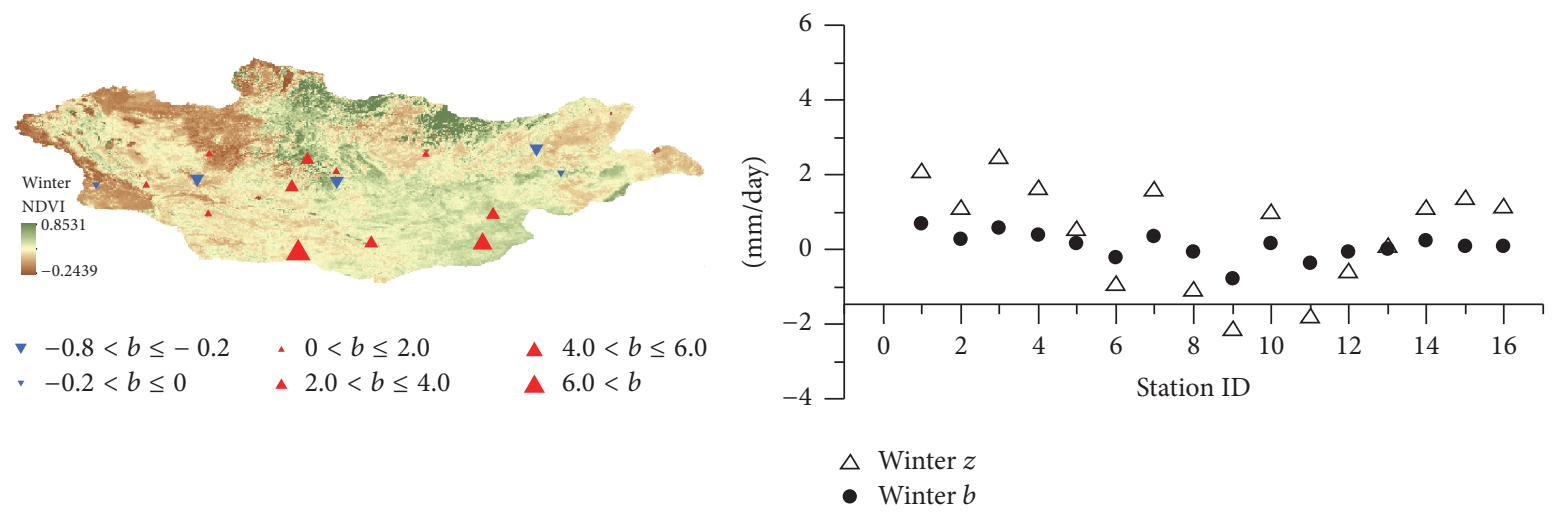

(e)

Figure 6: Theil-Sen's slope $b$ at sites atop the NDVI map for (a) annual, (b) spring, (c) summer, (d) autumn, and (e) winter.
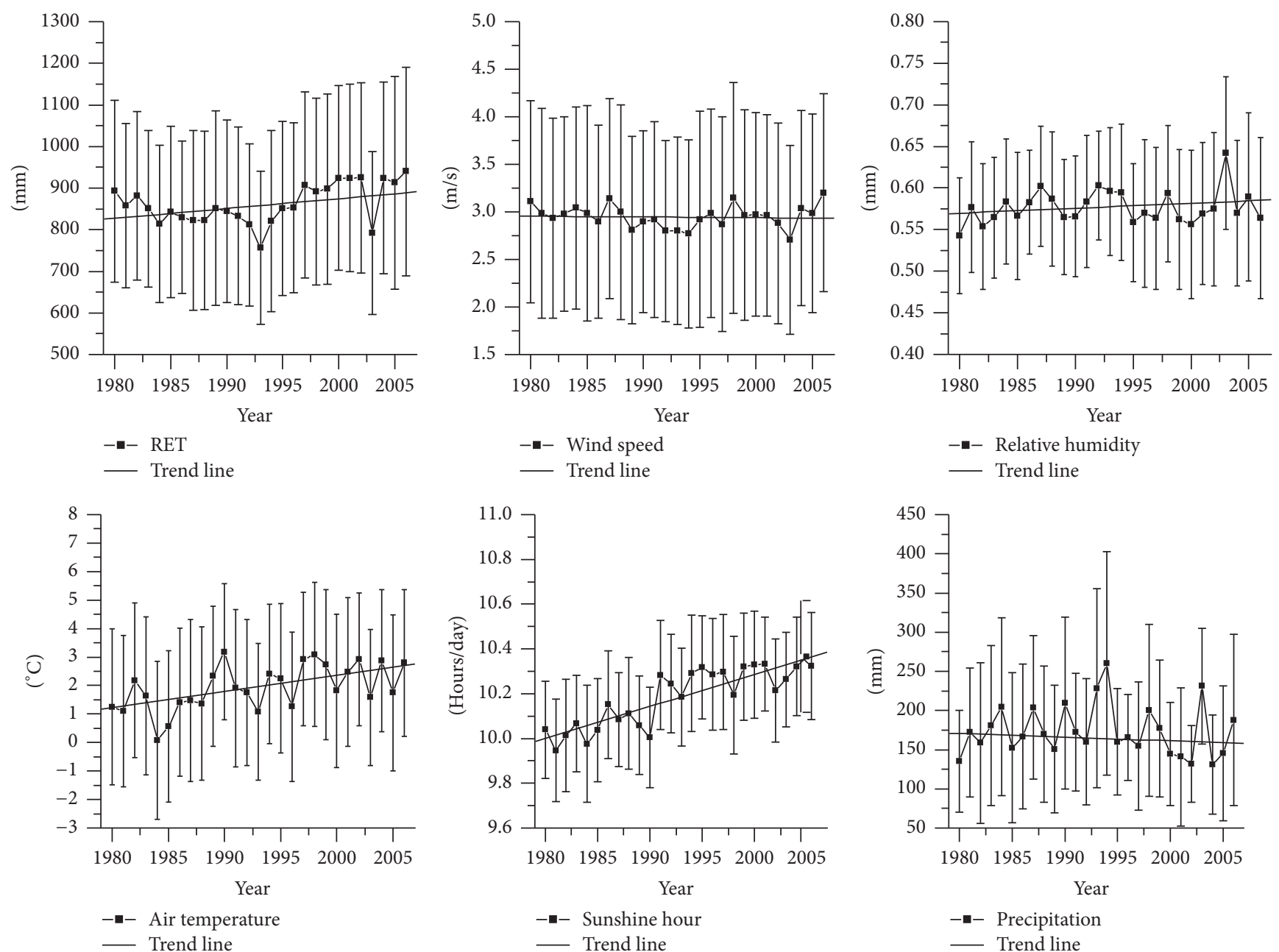

Figure 7: Annual variations and standard deviations of RET and related meteorological variables.

the contribution of the increases of RET. According to the Intergovernmental Panel on Climate Change (IPCC) Fifth Assessment Report, air temperature increased over the past several decades and predicted a possible increase in the future. Thus, RET may show an upward trend for decades.
Statistical results of the correlation analysis show that RET is negatively correlated with relative humidity and precipitation. On an annual level, the correlation between RET and precipitation is the most significant, although precipitation was not the parameter of the FAO P-M method. 


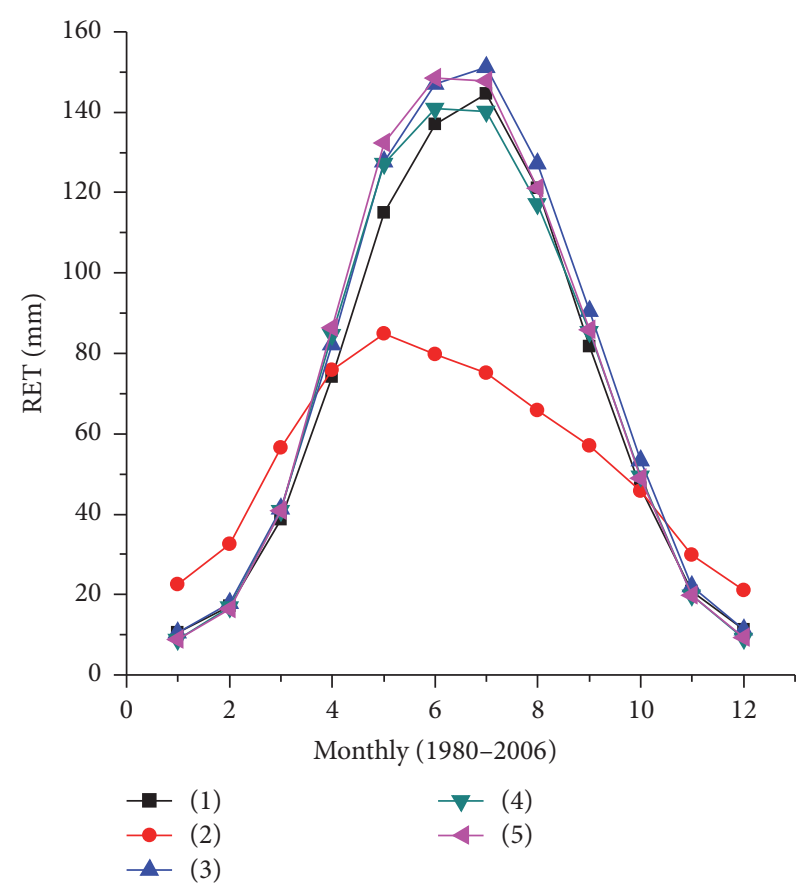

(a)

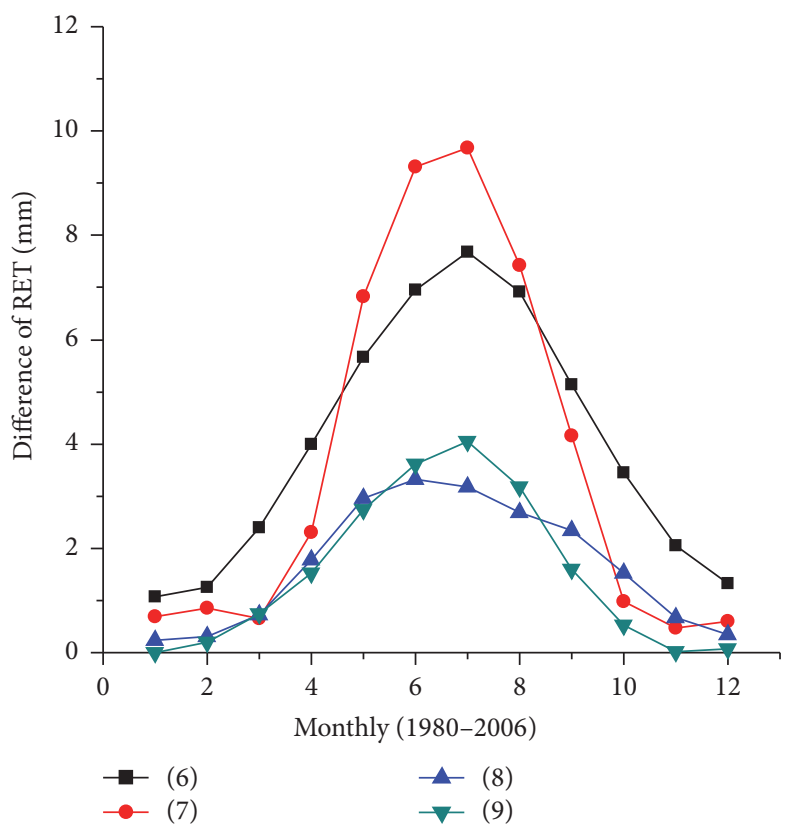

(c)

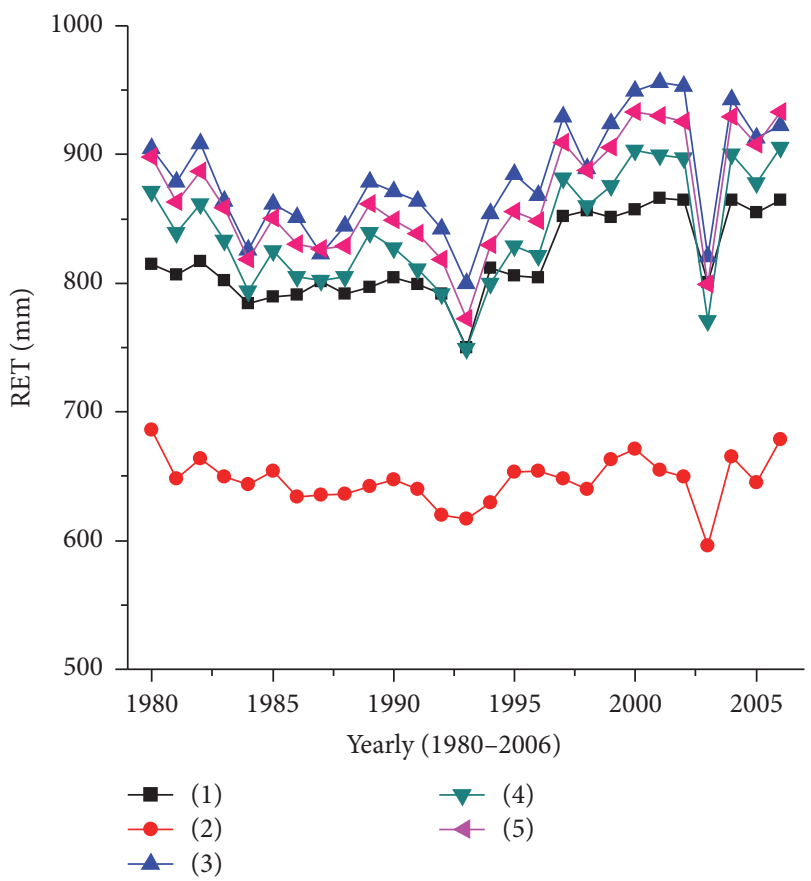

(b)

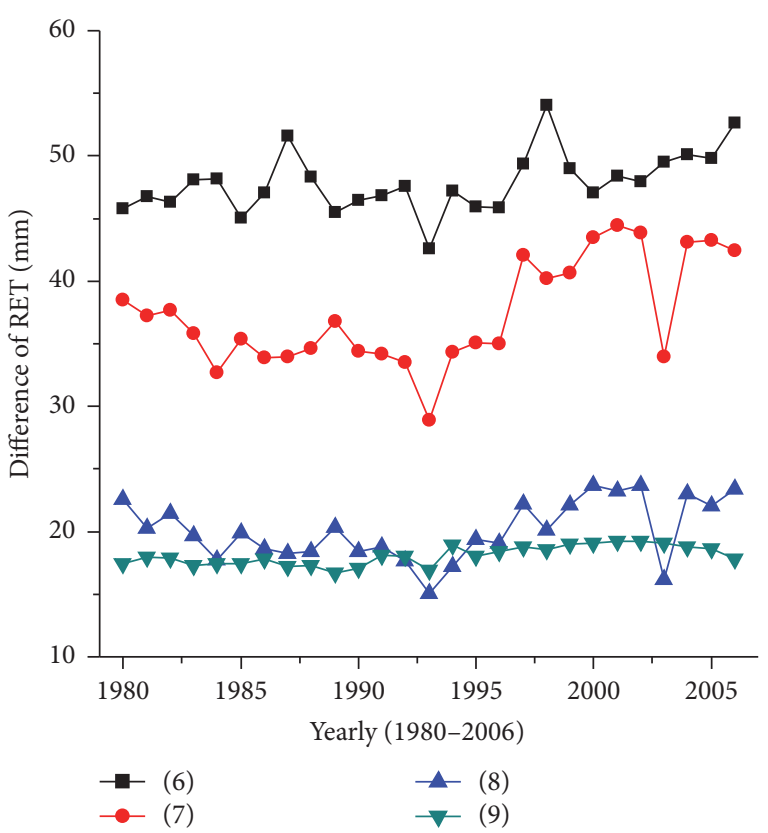

(d)

FIGURE 8: The original ((a) and (b), series 5) and generated RET on annual and monthly levels with the trend-removed relative humidity ((a) and (b), series 1), air temperature ((a) and (b), series 2), wind speed ((a) and (b), series 3), and sunshine hour ((a) and (b), series 4); the differences between the original and another generated RET with the $10 \%$ increment relative humidity ((c) and (d), series 6), air temperature ((c) and (d), series 7), wind speed ((c) and (d), series 8), and sunshine hour ((c) and (d), series 9).

The RET is larger than precipitation in amount and positively correlates with precipitation on a monthly scale, but with differing monthly amplitudes (Figure 2(a)). A negative correlation is high between precipitation and RET on an annual scale. The correlation coefficient of precipitation and RET reaches -0.648 at the significant level of 0.01 . When peaks of annual RET appear, relative low value of precipitation was found (Figure 7). The annual RET has increased over the past 27 years but precipitation did not increase. This implies that precipitation is not the main factor leading to increasing RET but is strongly related to variations of RET. The correlation coefficients of RET with relative humidity, air temperature, 
and precipitation were maximal of over 0.8 in summer. Also, the correlation coefficients of RET with wind and sunshine hour were found to be maximal in spring, although those maximal coefficients are lower than 0.8 .

The relationships between RET and all meteorological variables were analyzed by Irmak et al. [45] in detail. It was found that RET is significantly and inversely correlated to precipitation and relative humidity and positively correlated to air temperature, vapor pressure deficit, and solar radiation. These results are consistent with our aforementioned findings. Overall, there are different contributions of meteorological variables to RET on an annual level.

4.4. Impacts of Meteorological Variables on RET. The original and newly generated RETs data series are presented in Figures 8 (a) $-8(d)$ on monthly and annual scales. Figures 8(a) and 8 (b) display the original RET (series 5) and generated RETs by removing the trends from selected climatic variables, that is, relative humidity (series 1), air temperature (series 2), wind speed (series 3), and sunshine hour (series 4). TheilSen's slopes are $2.44,0.26,2.76$, and 2.56 , respectively, for the generated RETs, that is, with the trend removal cases of relative humidity, air temperature, wind speed, and sunshine hour, while the slope is 2.86 for the original RET. The smaller the slope $b$ of the generated RETs, the larger the difference of $b$ between the original and generated RETs. This indicates that the change of the generated RET with the smallest slope $b$ is the most significant and the influence of corresponding climatic variable on RET is also the greatest. It can be clearly found that there are prominent differences in slope $b$ between the original RET and generated RETs with air temperature trend removed. This indicates that air temperature strongly influences RET. Without the trend change of air temperature, the upward trend of generated RET became the slowest compared with other generated RETs by removing the trends from other climatic variables. The peak of the generated RET with air temperature trend removed appears earlier (Figure 8(a), series 2), and RET in warm seasons decreased sharply but had slight increases in cold seasons. Air temperature data became a constant after removing the trend change of air temperature, which led to no peak of air temperature in a year and contributed to increases of air temperature in cold seasons and decreases in warm seasons. The generated RET of air temperature also decreases by half compared with other generated RETs (Figure 8(b), series 2), which implies that air temperature is important to the amplitude of RET. This indicates that the influence of air temperature without trend change to RET was abated greatly. The variations of generated RETs with other trend-removed variables (relative humidity, wind speed, and sunshine hour) are relatively not distinct compared with the original RET. There was almost no change in cold seasons for the generated RETs of relative humidity (Figure $8(\mathrm{a})$, series 1 ), wind speed (Figure 8(a), series 3), and sunshine hour (Figure 8(a), series 4). In warm seasons, generated RETs peaks had a small drop and the generated RET of relative humidity had a larger drop early in the warm seasons than that of wind speed and sunshine hour. The slope $b$ value of generated RET with relative humidity trend removed is smaller than those with wind speed and sunshine hour, while its changing trend is larger than wind speed and sunshine hour (Figure 8(b)). This indicates that relatively humidity has a noticeable effect on RET in comparison with wind speed and sunshine hour.

Figures 8(c) and 8(d) show absolute differences between the original and the other generated RETs by adding selected climatic variables by $10 \%$ increments, that is, relative humidity (series 6), air temperature (series 7), wind speed (series 8), and sunshine hour (series 9). The differences between the original and another generated RET with increased air temperature by $10 \%$ are the largest in warm seasons, with a sharp rise in summer (Figure $8(\mathrm{c})$, series 7 ). The maximum differences occur between the original and generated RET with increased relative humidity (Figure $8(\mathrm{c})$, series 6 ) in cold seasons (spring and winter). This implies that in warm seasons the influence of air temperature on RET is the greatest, and in cold seasons the influence of relative humidity is the greatest. On an annual scale, the changes of generated RET with increased relative humidity (Figure 8(c), series 6) are the greatest, followed by air temperature (Figure 8(c), series 7 ), wind speed (Figure $8(\mathrm{c})$, series 8 ), and sunshine hour (Figure $8(\mathrm{~d})$, series 9 ). The relative humidity with $10 \%$ increment caused the most increases of RET, which indicates that the RET is the most sensitive to the size of relative humidity.

It can be concluded that relative humidity and air temperature exerted stronger influences on RET over the past 27 years while they exerted weaker influences in terms of wind speed and sunshine hour. Moreover, the RET is the most sensitive to the trend change of air temperature and the size of relative humidity.

\section{Conclusions}

In this study, the RET was calculated by the FAO P-M method in Mongolia from 1980 to 2006. The trend changes of RET for 16 stations on annual and seasonal scales were detected by nonparametric Mann-Kendall trend test and Theil-Sen's slope, respectively. The impacts of meteorological variables on RET were further analyzed. Significant upward trends have been detected in Mongolia over the past 27 years. The spatial pattern of RET is closely related to surface conditions such as vegetation indicated by NDVI. The highest RET is found in the south characterized with barren soils or deserts due to less vegetation influence and sufficient water supplement in local places. These results demonstrate that maximum changes for these stations occurred in center and south Mongolia. The analysis of RET data for these stations according to latitude and elevation was performed, which shows distinct latitude-belt and altitude-belt distribution of RET. The RET is strongly correlated with meteorological variables, especially with relative humidity and precipitation, and the magnitude is strongly influenced by air temperature. In addition, aridity indices and the small amount of precipitation imply severe drought in Mongolia. The results of these studies provide baseline for agriculture irrigation systems. On account of the limited and sparse stations 
and incomplete meteorological data, remote sensing data with high spatiotemporal resolution will be needed for the accurate study of RET. In future studies, physical models such as SEBS and TSEB, combined with remote sensing, will be considered to estimate and predict RET for a long term and for larger regions.

\section{Competing Interests}

The authors declare that there are no competing interests regarding the publication of this paper.

\section{Acknowledgments}

This study was supported by the National Major Scientific Project of China (2013CBA01803), the National Natural Science Foundation of China (41271086 and 41271081), and the Hundred Talents Program of the Chinese Academy of Sciences (51Y251571). The authors are grateful to Dr. Xiaodong $\mathrm{Wu}$ for his valuable comments.

\section{References}

[1] R. G. Allen, L. S. Pereira, D. Raes, and M. Smith, "Crop evapotranspiration-guidelines for computing crop water requirements," FAO Irrigation and Drainage Paper 56, Food and Agriculture Organization, Rome, Italy, 1998.

[2] W. Brutsaert and H. Stricker, "An advection-aridity approach to estimate actual regional evapotranspiration," Water Resources Research, vol. 15, no. 2, pp. 443-450, 1979.

[3] F. I. Morton, "Estimating evapotranspiration from potential evaporation: practicality of an iconoclastic approach," Journal of Hydrology, vol. 38, no. 1-2, pp. 1-32, 1978.

[4] M. Minacapilli, C. Cammalleri, G. Ciraolo, G. Rallo, and G. Provenzano, "Using scintillometry to assess reference evapotranspiration methods and their impact on the water balance of olive groves," Agricultural Water Management, vol. 170, pp. 49-60, 2016.

[5] M. G. Arellano and S. Irmak, "Reference (potential) evapotranspiration. I: comparison of temperature, radiation, and combination-based energy balance equations in humid, subhumid, arid, semiarid, and mediterranean-type climates," Journal of Irrigation and Drainage Engineering, vol. 142, no. 4, 2016.

[6] H. L. Penman, "Natural evaporation from open water, bare soil, and grass," Proceedings of the Royal Society of London Series AMathematical and Physical Sciences, vol. 193, no. 1032, pp. 120146, 1948.

[7] J. L. Monteith, "Evaporation and environment," Symposia of the Society for Experimental Biology, vol. 19, pp. 205-234, 1965.

[8] M. Garcia, D. Raes, R. Allen, and C. Herbas, "Dynamics of reference evapotranspiration in the Bolivian highlands (Altiplano)," Agricultural and Forest Meteorology, vol. 125, no. 1-2, pp. 67-82, 2004.

[9] M. Jabloun and A. Sahli, "Evaluation of FAO-56 methodology for estimating reference evapotranspiration using limited climatic data. Application to Tunisia," Agricultural Water Management, vol. 95, no. 6, pp. 707-715, 2008.

[10] S. M. Vicente-Serrano, C. Azorin-Molina, A. Sanchez-Lorenzo et al., "Reference evapotranspiration variability and trends in
Spain, 1961-2011," Global and Planetary Change, vol. 121, pp. 2640, 2014.

[11] M. M. Heydari, R. Aghamajidi, G. Beygipoor, and M. Heydari, "Comparison and evaluation of 38 equations for estimating reference evapotranspiration in an arid region," Fresenius Environmental Bulletin, vol. 23, no. 8, pp. 1985-1996, 2014.

[12] Y. Feng, N. Cui, L. Zhao, X. Hu, and D. Gong, "Comparison of ELM, GANN, WNN and empirical models for estimating reference evapotranspiration in humid region of Southwest China," Journal of Hydrology, vol. 536, pp. 376-383, 2016.

[13] D. Itenfisu, R. L. Elliott, R. G. Allen et al., "Comparison of reference evapotranspiration calculations across a range of climates," in Proceedings of the National Irrigation Symposium, pp. 214-227, Phoenix, Ariz, USA, 2000.

[14] Y. Dinpashoh, D. Jhajharia, A. Fakheri-Fard, V. P. Singh, and E. Kahya, "Trends in reference crop evapotranspiration over Iran," Journal of Hydrology, vol. 399, no. 3-4, pp. 422-433, 2011.

[15] S.-H. Zhao, Y.-H. Yang, F. Zhang et al., "Rapid evaluation of reference evapotranspiration in Northern China," Arabian Journal of Geosciences, vol. 8, no. 2, pp. 647-657, 2015.

[16] P. H. Talaee, B. S. Some'e, and S. S. Ardakani, "Time trend and change point of reference evapotranspiration over Iran," Theoretical and Applied Climatology, vol. 116, no. 3-4, pp. 639647, 2014.

[17] A.-E. Croitoru, A. Piticar, C. S. Dragotă, and D. C. Burada, "Recent changes in reference evapotranspiration in Romania," Global and Planetary Change, vol. 111, pp. 127-132, 2013.

[18] M. A. Mojid, R. P. Rannu, and N. N. Karim, "Climate change impacts on reference crop evapotranspiration in North-West hydrological region of Bangladesh," International Journal of Climatology, vol. 35, no. 13, pp. 4041-4046, 2015.

[19] D. Koffi and G. Komla, "Trend analysis in reference evapotranspiration and aridity index in the context of climate change in Togo," Journal of Water and Climate Change, vol. 6, no. 4, pp. 848-864, 2015.

[20] D. H. Burn and N. M. Hesch, "Trends in evaporation for the Canadian Prairies," Journal of Hydrology, vol. 336, no. 1-2, pp. 61-73, 2007.

[21] A. Bandyopadhyay, A. Bhadra, N. S. Raghuwanshi, and R. Singh, "Temporal trends in estimates of reference evapotranspiration over India," Journal of Hydrologic Engineering, vol. 14, no. 5, pp. 508-515, 2009.

[22] H. Tabari and P. H. Talaee, "Sensitivity of evapotranspiration to climatic change in different climates," Global and Planetary Change, vol. 115, pp. 16-23, 2014.

[23] A. Mossad and A. A. Alazba, "Simulation of temporal variation for reference evapotranspiration under arid climate," Arabian Journal of Geosciences, vol. 9, no. 5, 2016.

[24] M. Shadmani, S. Marofi, and M. Roknian, “Trend analysis in reference evapotranspiration using Mann-Kendall and Spearman's Rho tests in arid regions of Iran," Water Resources Management, vol. 26, no. 1, pp. 211-224, 2012.

[25] M. Gocic and S. Trajkovic, "Analysis of trends in reference evapotranspiration data in a humid climate," Hydrological Sciences Journal, vol. 59, no. 1, pp. 165-180, 2014.

[26] D. Jhajharia, Y. Dinpashoh, E. Kahya, V. P. Singh, and A. Fakheri-Fard, "Trends in reference evapotranspiration in the humid region of northeast India," Hydrological Processes, vol. 26, no. 3, pp. 421-435, 2012. 
[27] T. R. McVicar, M. L. Roderick, R. J. Donohue et al., "Global review and synthesis of trends in observed terrestrial nearsurface wind speeds: Implications for evaporation," Journal of Hydrology, vol. 416-417, pp. 182-205, 2012.

[28] L. Gong, C.-Y. Xu, D. Chen, S. Halldin, and Y. D. Chen, "Sensitivity of the Penman-Monteith reference evapotranspiration to key climatic variables in the Changjiang (Yangtze River) basin," Journal of Hydrology, vol. 329, no. 3-4, pp. 620-629, 2006.

[29] W. Wang, S. Peng, T. Yang, Q. Shao, J. Xu, and W. Xing, "Spatial and temporal characteristics of reference evapotranspiration trends in the haihe river basin, China," Journal of Hydrologic Engineering, vol. 16, no. 3, pp. 239-252, 2011.

[30] D. Jhajharia and V. P. Singh, "Trends in temperature, diurnal temperature range and sunshine duration in Northeast India," International Journal of Climatology, vol. 31, no. 9, pp. 1353-1367, 2011.

[31] V. T. Ambas and E. Baltas, "Sensitivity analysis of different evapotranspiration methods using a new sensitivity coefficient," Global Nest Journal, vol. 14, no. 3, pp. 335-343, 2012.

[32] H. B. Mann, "Nonparametric tests against trend," Econometrica, vol. 13, no. 3, pp. 245-259, 1945.

[33] R. N. Forthofer and R. G. Lehnen, Rank Correlation Methods, Griffin, London, UK, 1975.

[34] E. Pallé and C. J. Butler, "Sunshine records from Ireland: cloud factors and possible links to solar activity and cosmic rays," International Journal of Climatology, vol. 21, no. 6, pp. 709-729, 2001.

[35] J. Garbrecht, M. Van Liew, and G. O. Brown, "Trends in precipitation, streamflow, and evapotranspiration in the Great Plains of the United States," Journal of Hydrologic Engineering, vol. 9, no. 5, pp. 360-367, 2004.

[36] K. Zaninović and M. Gajić-Čapka, "Changes in components of the water balance in the Croatian lowlands," Theoretical and Applied Climatology, vol. 65, no. 1-2, pp. 111-117, 2000.

[37] H. Thiel, "A rank-invariant method of linear and polynomial regression analysis, part 3," Proceedings of Koninalijke Nederlandse Akademie van Weinenschatpen, vol. 53, pp. 1397-1412, 1950.

[38] P. K. Sen, "Estimates of the regression coefficient based on Kendall's tau," Journal of the American Statistical Association, vol. 63, pp. 1379-1389, 1968.

[39] Q. Mu, F. A. Heinsch, M. Zhao, and S. W. Running, "Development of a global evapotranspiration algorithm based on MODIS and global meteorology data," Remote Sensing of Environment, vol. 111, no. 4, pp. 519-536, 2007.

[40] Q. Mu, M. Zhao, and S. W. Running, "Improvements to a MODIS global terrestrial evapotranspiration algorithm," Remote Sensing of Environment, vol. 115, no. 8, pp. 1781-1800, 2011.

[41] G. B. Senay, J. P. Verdin, R. Lietzow, and A. M. Melesse, "Global daily reference evapotranspiration modeling and evaluation," Journal of the American Water Resources Association, vol. 44, no. 4, pp. 969-979, 2008.

[42] B. Gerelchuluun and J.-B. Ahn, "Air temperature distribution over Mongolia using dynamical downscaling and statistical correction," International Journal of Climatology, vol. 34, no. 7, pp. 2464-2476, 2014.

[43] D. Mutiibwa and S. Irmak, "AVHRR-NDVI-based crop coefficients for analyzing long-term trends in evapotranspiration in relation to changing climate in the U.S. high plains," Water Resources Research, vol. 49, no. 1, pp. 231-244, 2013.
[44] M. C. Zhou, H. Ishidaira, and K. Takeuchi, "Estimation of potential evapotranspiration over the Yellow River basin: reference crop evaporation or Shuttleworth-Wallace?" Hydrological Processes, vol. 21, no. 14, pp. 1860-1874, 2007.

[45] S. Irmak, I. Kabenge, K. E. Skaggs, and D. Mutiibwa, "Trend and magnitude of changes in climate variables and reference evapotranspiration over 116-yr period in the Platte River Basin, central Nebraska-USA," Journal of Hydrology, vol. 420-421, pp. $228-244,2012$. 

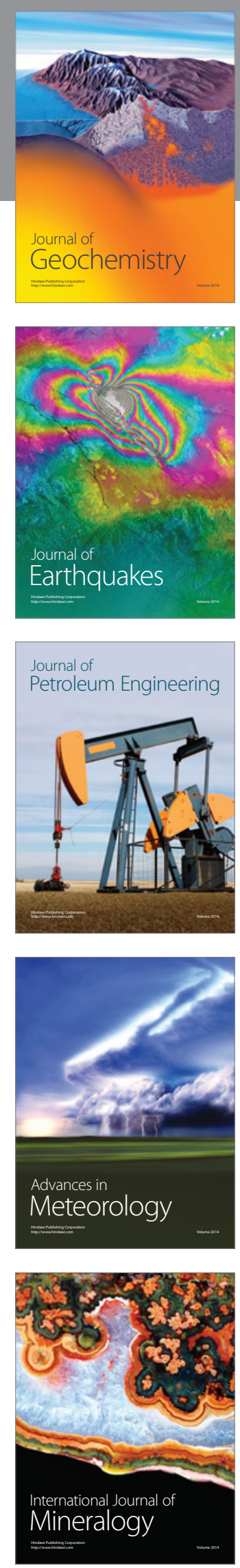
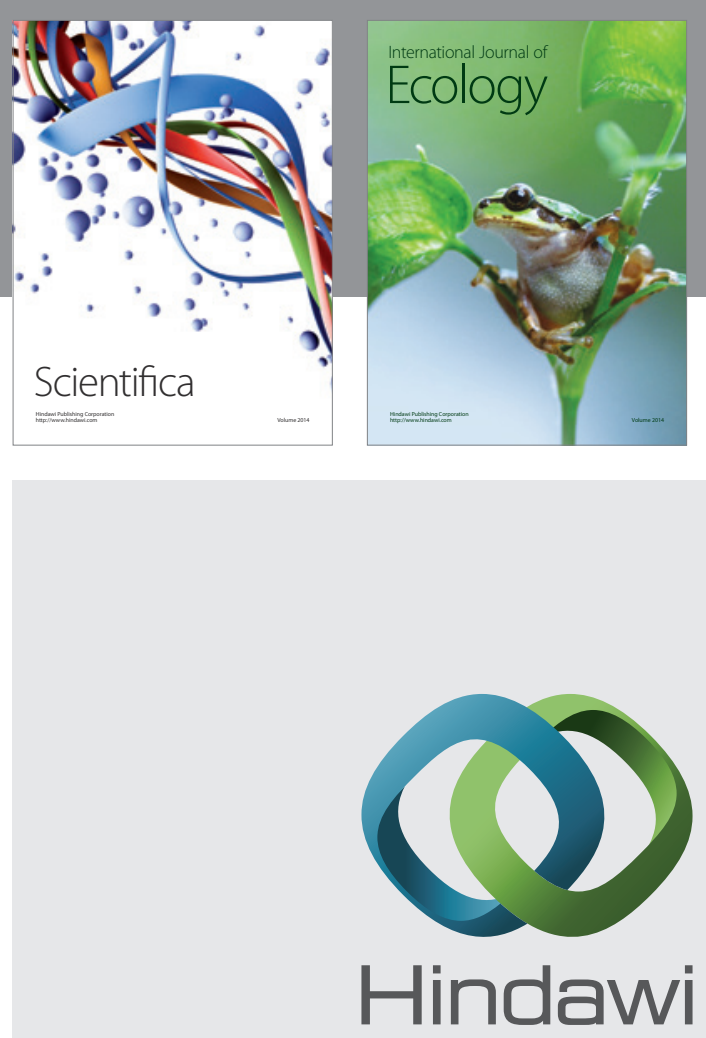

Submit your manuscripts at

http://www.hindawi.com
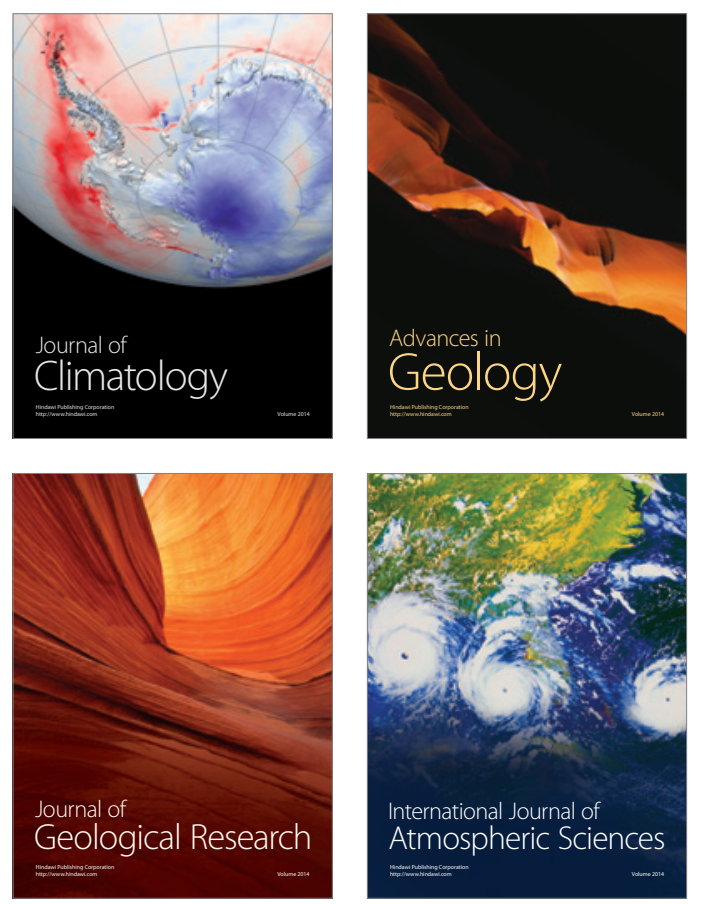

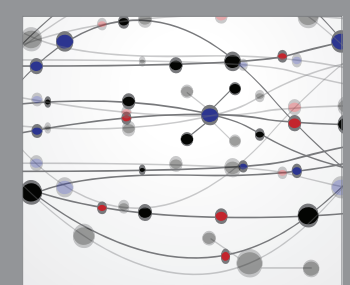

The Scientific

\section{World Journal}
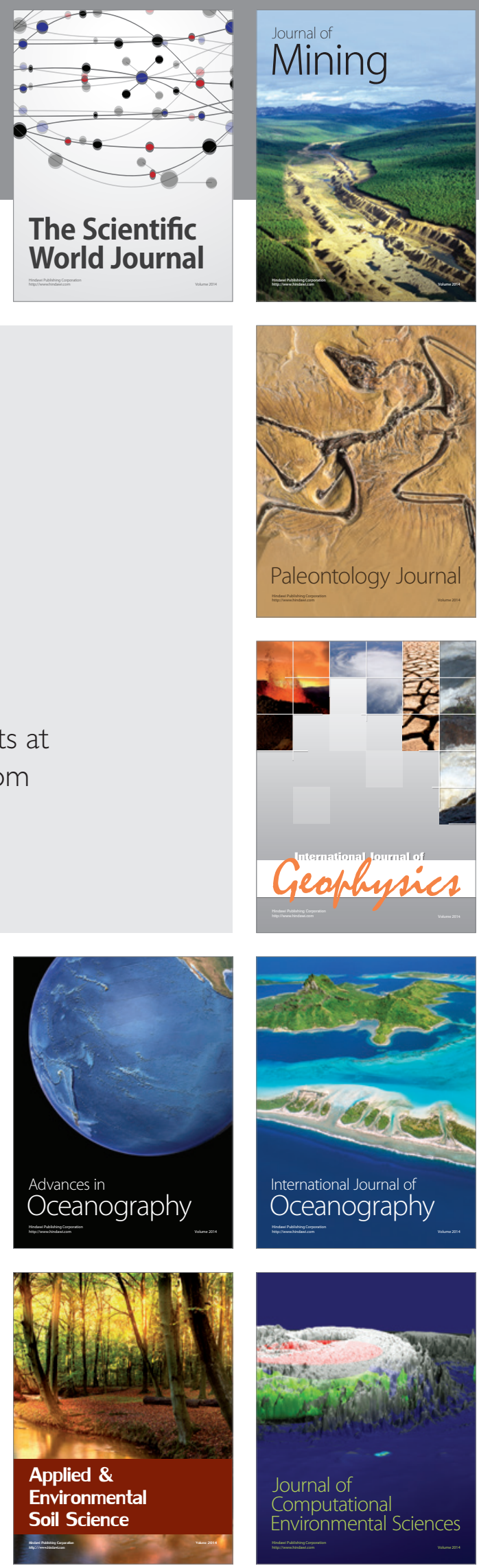